\title{
Imaging of pulmonary disease in scleroderma with J001X scintigraphy
}

P Diot, E Diot, E Lemarie, J L Guilmot, J L Baulieu, E Asquier, C Valat, A Delarue, A Le Pape

\begin{abstract}
Background - J001X is an acylated polygalactoside isolated from the membrane of Klebsiella and able to interact with macrophages, mainly in their activated state. The aim of the present study was to determine the ability of $99 \mathrm{~m}$-labelled technetium ${ }^{\left.{ }^{99 m} \mathrm{Tc}\right)-\mathrm{J} 001 \mathrm{X} \text { scintigraphy to }}$ image pulmonary disease, defined by high resolution computed tomographic scanning and pulmonary function tests, in patients suffering from scleroderma. Methods - Patients were considered to have pulmonary disease when they had at least two positive signs on high resolution computed tomography, or a decrease in lung volume and single breath carbon monoxide transfer, or both, with no disease process other than scleroderma in their medical history. Positive J001X scintigraphic imaging was defined by symmetrical bilateral pulmonary fixation three and five hours after inhalation of ${ }^{99 \mathrm{~m}} \mathrm{Tc}-\mathrm{J} 001 \mathrm{X}$. J001X scintigraphic results were compared with disease activity as indicated by bronchoalveolar lavage (BAL) fluid lymphocytosis.

Results - Seventeen patients were studied, in 12 of whom J001X scintigraphy was positive. There was no correlation between BAL lymphocytosis and J001X scintigraphic findings, nor between $B A L$ and pulmonary scleroderma. This was not surprising because of the high specificity of macrophage targeting by J001X. Conclusions - Follow up of a larger population over a longer period is needed to establish whether there is a prognostic value for positive J001X scintigraphic findings in scleroderma.
\end{abstract}

(Thorax 1994;49:504-508)

Scleroderma is a systemic disease characterised by an excess of collagen in the skin and other organs. ${ }^{2}$ Pulmonary involvement, assessed histologically, can be detected in $70 \%{ }^{3}$ to $100 \%{ }^{4}$ of patients. The mechanisms underlying pulmonary sclerosis seem to be common to scleroderma and to fibrosis from other causes; alveolar and interstitial injury are followed by collagen infiltration. ${ }^{5}$ Clinical and radiological manifestations appear some time after the beginning of the disease. ${ }^{6-8}$ Pulmonary involvement should be detected early with the aim of protecting patients from tobacco and other environmental contaminants and to consider immunosuppressive treatment. ${ }^{6}$
Several techniques, including the total pulmonary diffusing capacity of carbon monoxide (TLCO), ${ }^{99 \mathrm{~m}}$ Tc-DTPA scintigraphy, ${ }^{7}$ gallium67 scintigraphy ${ }^{10}$ and, more importantly, thin section high resolution computed tomographic (HRCT) scanning and bronchoalveolar lavage (BAL) fluid analysis ${ }^{81112}$ have proved sensitive for detecting pulmonary disease in patients with scleroderma. Neutrophil or lymphocytic alveolitis, or both, associated with moderate eosinophilia are the most common abnormalities detected in BAL fluid from these patients. ${ }^{12}$ However, alveolar macrophages are involved in the fibrosing process through the secretion of interleukin $1,{ }^{13}$ fibronectin, ${ }^{14}$ macrophage derived growth factor, ${ }^{15}$ and superoxide anion. ${ }^{16}$ These activated cells are recruited to the lung before lymphocytes and neutrophils ${ }^{16}$ and in vivo macrophage targeting appears to be a potential strategy for the scintigraphic imaging of such cases.

$\mathrm{J} 001 \mathrm{X}$, an acylated polygalactoside isolated from the membrane of a non-pathogenic and non-encapsulated strain of Klebsiella pneumoniae, was developed to target macrophages selectively. ${ }^{17}$ This molecule is able to interact with macrophages, mainly in their activated state, and in vitro studies have shown that CD11b/CD18 and CD14 molecules are involved in cell-J001X interaction. ${ }^{18}$ In a recent unpublished study (P Haslam, personal communication) binding to ex vivo human alveolar macrophages using biotinylated J001X and the streptavidin-phycoerythrin amplification system in flow cytometry was described. The study was performed at three different concentrations of J001X in the presence or absence of an excess of unlabelled J001X in different models of pulmonary inflammation. The results confirmed that pulmonary inflammatory diseases are characterised by a recruitment of $\mathrm{J} 001 \mathrm{X}$ binding macrophages, but without increased expression of J001X receptors. The binding was concentration dependent and totally displaced by unlabelled J001X. In vivo ${ }^{99 \mathrm{~m}} \mathrm{Tc}$-J001X scintigraphy has proved to be useful for imaging mediastinal lymph nodes and pulmonary disease caused by experimental chronic berylliosis in baboons ${ }^{19}$ and sarcoidosis in man..$^{2021}$

The aim of the present study was to determine the ability of J001X scintigraphy to image pulmonary disease, defined according to HRCT scanning, TLCO, and BAL fluid analysis, in patients suffering from scleroderma. 


\section{Methods}

\section{STUDY POPULATION}

Seventeen patients (16 women) aged 23-81 years suffering from scleroderma, with or without clinical respiratory symptoms, admitted consecutively to our institution between October 1990 and February 1991 were included in the study. Scleroderma was defined according to the American Rheumatism Association criteria. ${ }^{22}$ All patients gave written informed consent and the study was approved by the institution ethics committee. Thirteen patients were non-smokers and two had stopped one and three years previously. Two patients were current smokers (eight and 20 pack years). None had a recent past history or signs of respiratory infection at the time of the study. All had normal renal function and two had chronic hepatitis. The time from diagnosis to beginning the study ranged from one month to 37 years with a mean of 12 years. All patients had Raynaud's phenomenon; seven had CREST syndrome ${ }^{23}$ and three Sjögren's syndrome. ${ }^{24}$ The extent of cutaneous disease was classified in two ways ${ }^{25}$ : acroscleroderma (seven patients) and proximal ascending scleroderma (10 patients). No patient had truncal scleroderma. Treatment included corticosteroids (one patient), non-steroidal antiinflammatory drugs (one patient), calcium channel blockers (10 patients), factor XIII (three patients), parenteral prostacyclin (two patients), colchicine (two patients), sulphasalazine (one patient), and D-penicillamine (one patient).

A previous study including a control group had been performed in patients with sarcoidosis. ${ }^{21}$ In the control group we showed that lung clearance was always complete five hours after J001X inhalation; neither localised nor diffuse activity was observed in the thorax at five hours. In view of this previous experience a control group was not included in the present study.

\section{COMPUTED TOMOGRAPHIC SCANNING}

High resolution computed tomographic (HRCT) scans were carried out with a Somatom HIQ CT scanner at an exposure time of two seconds. Two millimetre thick slices performed at the end of inspiration were obtained at intervals of $10 \mathrm{~mm}$ on a $512 \times 512$ matrix from the apices to the bases. Prone sections were obtained when false positive results due to gravity dependent perfusion were suspected on supine sections.

HRCT scans were read by two independent radiologists blind to the results of other diagnostic studies. To assess interstitial disease the presence of micronodules, ground glass, septal thickening, subpleural linear opacities, and honeycombing appearance were noted.

\section{PULMONARY FUNCTION TESTS}

Forced inspiratory and expiratory flow volume curves and absolute lung volumes were measured in a constant pressure plethysmograph (Sensor Medics 2800, USA). A 10 second single breath carbon monoxide transfer test (TLCO, Morgan, UK) was measured on the day of each scintigraphic scan. Results were expressed as percentages of normal values. ${ }^{2627}$ Expiratory flow rates, total lung capacity, and ThCo were considered to be decreased if they were less than $15 \%$ of normal values.

\section{J001X SCINTIGRAPHY}

One mg freeze dried J001X (Laboratoire Pierre Fabre, France) was labelled with 1100 $\mathrm{MBq}$ sodium ${ }^{99 \mathrm{~m}} \mathrm{Tc}$ pertechnetate reduced in the presence of $125 \mu \mathrm{g}$ stannous fluoride (Hepatate II, Amersham, UK). Patients inhaled the $4 \mathrm{ml}$ radiolabelled J001X preparation as an aerosol in a specially devised aspiration hood (ESI, France) using an ultrasound TV 6000 inhaler (Siemens, West Germany) operating at $110 \mathrm{kHz}$ as previously described. ${ }^{21}$ Three and five hours after inhalation, anterior and posterior $128 \times 128$ pixel images were recorded with a LFOV gamma camera (Siemens, Germany) equipped with a high resolution, low energy parallel collimator and connected to a S 2000 computer for image processing (Sopha Medical, France). Each of the acquisition (anterior and posterior views) recorded three and five hours after inhalation was interpreted independently by two observers (PD and JLB). Background was not subtracted. Contrast was digitally enhanced by scaling the maximum intensity to a lower value than the maximum count. Positivity of J001X scintigraphy was defined by symmetrical bilateral pulmonary fixation three and five hours after inhalaton of ${ }^{99 \mathrm{~m}} \mathrm{Tc}-\mathrm{J} 001 \mathrm{X}$. According to our previous experience of J001X scintigraphy in control subjects, ${ }^{21}{ }^{99 m} \mathrm{Tc}$-J001X activity localised in the oesophagus, stomach, heart, and breast was considered normal. Negative J001X scintigraphic findings were characterised by the absence of any thoracic activity at five hours as previously described. ${ }^{20}$

BRONCHOALVEOLAR LAVAGE (BAL)

Bronchoalveolar lavage was performed within 10 days of J001X scintigraphy according to the recommendations of the European Respiratory Society. ${ }^{28}$ Briefly, $150 \mathrm{ml}$ sterile saline were infused in $20 \mathrm{ml}$ aliquots at room temperature to the lingula or the middle lobe and immediately gently reaspirated. The first aliquot was collected separately and not used for analysis. Percentage of recovery was noted. After centrifugation, lavaged fluid cells were analysed for total numbers and differential counts. After staining with modified Wright-Giemsa stain, a minimum of 300 cells was counted to obtain a differential cell count. According to our own laboratory controls lymphocytes in BAL were considered to be increased when they constituted more than $20 \%$ of the total cells recovered.

\section{DATA ANALYSIS}

Patients were considered to have pulmonary scleroderma when they had at least two posi- 
Table 1 Results in 12 patients with abnormal HRCT scans and pulmonary function tests

\begin{tabular}{|c|c|c|c|c|}
\hline Patient & $P F T$ & $H R C T$ & $B A L$ & $\mathcal{F 0 0 1 X}$ \\
\hline 1 & $\begin{array}{l}\text { Restrictive syndrome } \\
\text { Decrease in TLCo }\end{array}$ & $\begin{array}{l}\text { Bilateral interstitial } \\
\text { lung disease }\end{array}$ & L $75 \%, N 4 \%$ & BLF \\
\hline 2 & Obstructive syndrome & $\begin{array}{l}\text { Left upper lobe } \\
\text { interstitial disease }\end{array}$ & L $38 \%$, N $5 \%$ & BLF \\
\hline 3 & $\begin{array}{l}\text { Restrictive syndrome } \\
\text { Decrease in TLCo }\end{array}$ & $\begin{array}{l}\text { Mild right lung interstitial } \\
\text { disease }\end{array}$ & L $23 \%, N 4 \%$ & Negative \\
\hline 4 & $\begin{array}{l}\text { Restrictive syndrome } \\
\text { Decrease in TLCO }\end{array}$ & $\begin{array}{l}\text { Bilateral interstitial } \\
\text { lung disease }\end{array}$ & L $1 \%$, N $1 \%$ & BLF \\
\hline 5 & Normal & $\begin{array}{l}\text { Bilateral interstitial } \\
\text { lung disease }\end{array}$ & L $1 \%$, N $0 \%$ & BLF \\
\hline 6 & Obstructive syndrome & $\begin{array}{l}\text { Mild bilateral interstitial } \\
\text { lung disease }\end{array}$ & L $2 \%$, N $0 \%$ & BLF \\
\hline 7 & $\begin{array}{l}\text { Restrictive syndrome } \\
\text { Decrease in TLCO }\end{array}$ & $\begin{array}{l}\text { Centrilobular } \\
\text { emphysema }\end{array}$ & L $3 \%$, N $1 \%$ & BLF \\
\hline 8 & $\begin{array}{l}\text { Restrictive syndrome } \\
\text { Decrease in TLCO }\end{array}$ & $\begin{array}{l}\text { Left upper lobe } \\
\text { interstitial lung disease }\end{array}$ & L $10 \%, N 5 \%$ & BLF \\
\hline 9 & Normal & $\begin{array}{l}\text { Mild bilateral interstitial } \\
\text { lung disease }\end{array}$ & L $1 \%$, N $0 \%$ & BLF \\
\hline 10 & $\begin{array}{l}\text { Obstructive syndrome } \\
\text { Decrease in TLco }\end{array}$ & $\begin{array}{l}\text { Bilateral upper lobe } \\
\text { interstitial lung disease }\end{array}$ & L $4 \%, N_{1 \%}$ & Negative \\
\hline 11 & $\begin{array}{l}\text { Restrictive syndrome } \\
\text { Decrease in TLCo }\end{array}$ & Not available & Not available & BLF \\
\hline 12 & Obstructive syndrome & $\begin{array}{l}\text { Bilateral upper lobe } \\
\text { interstitial lung disease }\end{array}$ & Not available & BLF \\
\hline
\end{tabular}

PFT = pulmonary function tests $; \mathrm{BAL}=$ bronchoalveolar lavage $\mathrm{L}=$ lymphocytes HRCT $=$ high resolution computed tomography; $\mathrm{N}=$ neutrophils; $\mathrm{BLF}=$ bilateral lung fixation; $\mathrm{TLCO}=$ carbon monoxide transfer factor.
Table 2 Results in 5 patients with normal pulmonary function tests and HRCT scans

\begin{tabular}{lll}
\hline Patient & BAL & $\mathcal{F 0 0 1 X}$ \\
\hline 13 & L $4 \%$, N $0 \%$ & Bilateral lung fixation \\
14 & L $27 \%$, N $2 \%$ & Negative \\
15 & L $4 \%$, N $0 \%$ & Bilateral lung fixation \\
16 & L $4 \%$, N $\%$ & Negative \\
17 & L $18 \%$, N $1 \%$ & Negative \\
\hline
\end{tabular}

$\mathrm{BAL}=$ bronchoalveolar lavage; $\mathrm{L}=$ lymphocytes; $\mathrm{N}=$ neutrophils; HRCT $=$ high resolution computed tomography.

had more than $20 \%$ lymphocytes in the BAL fluid.

Thus, 12 of 17 patients had positive J001X scintigraphic results. Ten of these patients were considered to have pulmonary scleroderma with abnormal pulmonary function tests or HRCT scans, or both, and two were considered to have no signs of pulmonary scleroderma. There was no relation between BAL lymphocytosis and J001X scintigraphy results, or between BAL lymphocytosis and pulmonary scleroderma: four patients had more than $20 \%$ lymphocytes in the BAL fluid and two of these had positive J001X scintigraphic results.

tive signs on HRCT scanning or a decrease in TLCo and lung volumes, or both, without any event other than scleroderma in their medical history.

The J001X scintigraphy result was analysed, taking into account the presence or absence of pulmonary involvement as described above, and compared with BAL fluid analysis.

\section{Results}

Twelve patients were considered to have pulmonary scleroderma with abnormal pulmonary function tests or HRCT scans, or both (patients 1-12; table 1). Ten of these (patients $1-6,8,9,10$, and 12) had at least two signs of interstitial lung disease on HRCT scanning. No patient had honeycombing. In all cases there was perfect agreement between the two observers. Interstitial disease was located either in both lungs (patients $1,4,5,6,9$ ), predominantly in the upper lobes (patients 10 and 12), or in one upper lobe (patients 2 and 8 ). Patient 7 had bilateral axillary pleural thickening and centrilobular emphysema. The restrictive syndrome in this patient, associated with a decrease in TLCo, could not be related to centrilobular emphysema and was strongly suggestive of interstitial disease. In this group of 12 patients with pulmonary scleroderma J001X scintigraphic scans were positive in 10 patients (nos 1, 2, 4-9,11, and 12).

Three patients (nos 1-3) had more than $20 \%$ lymphocytes in the BAL fluid. Two of these patients had positive J001X scintigraphic results. Nine patients had normal (patients 4-10) or unavailable (patients 11 and 12) BAL results; J001X scintigraphy was positive in eight of these.

Five patients (nos 13-17) had no sign of pulmonary scleroderma (normal pulmonary function tests and HRCT scans) (table 2). Two of these patients (nos 13 and 15) had positive J001X scintigraphic scans; one patient (no. 14)

\section{Discussion}

In this study in patients with scleroderma J001X scintigraphic scans were positive in 10 of the 12 patients suspected of having pulmonary disease and in two of the five patients without pulmonary disease as defined by HRCT scanning and lung function.

The "gold standard" for assessing pulmonary involvement in scleroderma is still considered to be open lung biopsy. Nevertheless, a recent study has suggested that HRCT scanning may be as good, and it has the advantage of imaging the entire lungs. ${ }^{29}$ For ethical reasons patients included in this study who were all clinically asymptomatic were not submitted to a biopsy. HRCT scanning and pulmonary function tests, including $\mathrm{T}_{\mathrm{LCO}}$, which are sensitive tests of pulmonary involvement in patients suffering from scleroderma, ${ }^{8911}$ were chosen as reference tests. Nevertheless, the specificity of some signs on HRCT scans, such as septal thickening or subpleural linear opacities, is controversial when they occur in isolation. This is why we considered that at least two signs of interstitial lung disease were necessary apart from honeycombing which is specific to fibrosis. Scleroderma is known to induce vascular damage and depression in TLCO which is not specific for parenchymal disease. Patients were considered to have pulmonary scleroderma when a decrease in TLCO was associated with reduced lung volumes and two positive signs on HRCT scanning without any event other than scleroderma in their medical history. BAL was also performed because the occurrence of subclinical alveolitis during scleroderma has recently been demonstrated. ${ }^{30}$

$\mathrm{J} 001 \mathrm{X}$ is a fully characterised $34 \mathrm{kDa}$ acylated poly $(1,3)$ galactoside isolated from Klebsiella membranes which is able to bind selectively to recruited macrophages. ${ }^{19}$ Because of its amphiphatic properties ${ }^{99 \mathrm{~m}} \mathrm{Tc}-\mathrm{J} 001 \mathrm{X}$ is 
absorbed through the respiratory tract and can be administered as an aerosol. Studies are now in progress to determine the actual site of absorption of J001X. In previous studies the TV6000 ultrasonic nebuliser has been shown to produce J001X particles ranging from $5 \mu \mathrm{m}$ to $13 \mu \mathrm{m}$ in diameter. ${ }^{20}$ Nevertheless, studies of the kinetics of J001X in peripheral blood have shown complete absorption of the molecule up to three hours after its inhalation. Moreover, peripheral deposition obtained with smaller mass median aerodynamic diameter particles, as achieved with higher frequency ultrasonic nebulisers such as the DP100 (DP Medical, $2.4 \mathrm{MHz}$, France) or Fisoneb (Fisons, 1.3 MHz, France), leads to delayed clearance and therefore altered capacity of J001X scintigraphy to image lesions within the lungs. It is clear therefore that absorption of J001X occurs in the upper airways, or even in the nose if patients inhale through a facial mask. Characterisation of the site of absorption and metabolism of the molecule is of particular importance in developing a systemic route of administration which would be easier to use.

Some anatomical localisations of activity on J001X scintigraphy were considered to be physiological or of little significance in view of the known pathophysiology of scleroderma, including digestive (oesophagal and gastric) contamination from swallowing part of the radiolabel. Background resulting from this central activity was particularly high in patients in this study, probably because of abnormal oesophageal kinetics. Heart imaging corresponded to the circulating part of the aerosol after absorption. Some uptake by the breast was also frequently observed in normal subjects.

Twelve of the 17 patients studied had positive J001X scintigraphy results. The fact that pulmonary fixation was bilateral and symmetrical in 12 patients fits the hypothesis that subclinical alveolitis during connective tissue disease, especially scleroderma, is a diffuse phenomenon involving both lungs. ${ }^{31}$ In patients 1 and 2 the results of HRCT scanning, BAL fluid examination, and J001X scintigraphy agreed, suggesting pulmonary disease. In patient 3 there was evidence of interstitial injury from both HRCT scans and pulmonary function tests, and also BAL lymphocytosis. Nevertheless, J001X scintigraphy was normal. In these patients a positive scintigraphic scan could be interpreted as reflecting its capacity to image the fibrotic process by targeting recruited macrophages. Eight other patients (nos $4-9,11$, and 12) with pulmonary scleroderma had positive J001X scintigraphic scans and normal (or not available in two cases) BAL findings. This shows that macrophage activation precedes recruitment of other cells, as reported in previous studies. ${ }^{16}$

J001X scintigraphy showed bilateral lung uptake in two cases among five patients without evidence of pulmonary scleroderma from HRCT scans and pulmonary function tests. This may represent early pulmonary disease in these patients.
Studies are now also in progress to define a quantitative or semiquantitative method for analysis of J001X scintigraphy based on the model of that used to process gallium scintigraphy. ${ }^{32} 33$ Only a prolonged follow up of a large population could provide an answer concerning the prognostic value of positive J001X scintigraphy and may provide a better knowledge of the process involving macrophages during pulmonary involvement of scleroderma.

The authors thank Drs Philippe Anthonioz, Eric Boissinot, and Hassane Moumouni for technical assistance, Sylvie Lefrançois for preparing the manuscript, and Doreen Raine for editing the English. They also thank Dr Patricia Haslam for her helpful advice on the performance of J001X binding studies on alveolar macrophages.

1 Fleishmajer R, Perlich JS, Reeves JRT. Cellular infiltrates in scleroderma skin. Arthritis Rheum 1977;20:975-84.

2 Bartnett AJ. The systemic involvement in scleroderma. Med f Aust 1977;2:659-62.

3 D'Angelo W, Fries J, Masi A, Schulman L. Pathologic observations in systemic sclerosis (scleroderma). $\mathrm{Am} \mathcal{F}$ Med 1969;46:428-40.

4 Weaver AL, Divertie MB, Titus JL. Pulmonary scleroderma. Dis Chest 1968;54:490-8.

5 Crystal RG, Gadek JE, Ferrans VJ, Fulmer JD, Line BR, Hunninghake GW. Interstitial lung disease: current concepts of pathogenesis, staging and therapy. $A m \mathcal{F} \mathrm{Med}$ 1981;70:542-68.

6 Silver RM, Miller KS, Kinsella MB, Smith EA, Schabel SI. Evaluation and management of scleroderma lung disease using bronchoalveolar lavage. $A m$ f Med 1990;88:470-6.

7 Harrisson NK, Glanville AR, Strickland B, Haslam PL, Corrin B, Addis BJ, et al. Pulmonary involvement in systemic sclerosis: the value of early changes by thin
sections, CT scan, bronchoalveolar lavage and ${ }^{99 m} \mathrm{Tc}$ DTPA clearance. Respir Med 1989;83:403-14.

8 Schurawitzki H, Stiglbauer R, Graninger W, Herold C, Pölzleitner D, Burghuber OC, et al. Interstitial lung disease in progressive systemic sclerosis: high resolution disease in progressive systemic sclerosis: high resol

9 Bagg LR, Hughes DTP. Serial pulmonary function tests in progressive systemic sclerosis. Thorax 1979;32:224-8.

10 Baron M, Feiglin D, Hyland R, Urowitz MB, Shiff B. 67-Gallium lung scans in progressive systemic sclerosis.
, Feiglin $D$, Hyland $R$, Urowitz $M B$, Shiff $B$. Arthritis Rheum 1983;26:969-74.

11 Strickland B, Strickland NH. The value of high definition, narrow section computed tomography in fibrosing alveolitis. Clin Radiol 1988;39:589-94.

12 Silver RM, Metcalf JF, Stanley JH, Carwile Leroy E. Interstitial lung disease in scleroderma. Arthritis Rheum 1984;27:1254-62.

13 Edelson JD, Hyland RH, Ramsden M, Chamberlain DW, Kortan P, Meindock HO, et al. Lung inflammation in scleroderma: clinical, radiographic, physiologic and cytopathologic features. $\mathcal{F}$ Rheumatol 1985;12:957-63.

14 Kinsella MB, Smith EA, Miller KS, Le Roy EC, Silver RM. Spontaneous production of fibronectin by alveolar RM. Spontaneous production of fibronectin by alveolar macrophages in patien

15 Rossi G, Bitterman P, Rennard S, Ferrans V, Crystal R. Evidence for chronic inflammation as a component of the interstial lung disease associated with progressive systemic sclerosis. Am Rev Respir Dis 1985;131:612-7.

16 Wallaert B, Bart F, Aerts C, Ouaissi A, Hatron PY, Tonnel $\mathrm{AB}$, et al. Activated alveolar macrophages in subclinical pulmonary inflammation in collagen vascular diseases. Thorax 1988;43:24-30.

17 Le Pape A. The targeting of macrophages with bacterial proteoglycans: a new strategy for the scintigraphic imaging of tumours and inflammatory lesions. Eur $₹ \mathrm{Nucl}$ Med 1989;15:424.

18 Hmama A, Normier G, Kouassi E, Flacher M, Binz H, Revillard JP. Binding of a membrane proteoglycan from Revillard JP. Binding of a membrane proteoglycan from Klebsiella pneumoniae and its chemically-defined derivat-

19 Diot P, Le Pape A, Nolibe D, Normier G, Binz H, Revillard JP, et al. Scintigraphy with J001 Klebsiella membrane glycolipopeptide for the early diagnosis of chronic berylliosis. Results in an experimental model of berylliosis in baboons. Br $\mathcal{F}$ Ind Med 1992;49:359-64.

20 Diot $P$, Lemarie E, Le Pape A, Peltier P, Caillat-Vigneron N. In: Diot P, Baulieu JL, Lemarie E, eds. Nuclear medicine and lung diseases. Paris: Springer Verlag, 1993:57-78.

21 Diot P, Lemarie E, Baulieu JL, Jubault C, Pascal S, Vaillant $\mathrm{L}$, et al. Scintigraphy with radiolabelled J001 glycolipopeptide: a new approach for sarcoidosis imaging. Chest 1992;102:670-6.

22 Masi AT, Rodnan GP, Medsger TA, Altmann RD, D'angelo WA, Fries JF, et al. Preliminary criteria for the classification of systemic sclerosis (scleroderma). Arthritis Rheum 1980;23:581-90. 
23 Le Roy EC. Scleroderma (systemic sclerosis). In: Kelley WN, Harris ED, Ruddy S, Scledge CB, eds. Textbook rheumatology. Philadelphia: Saunders, 1985:1183-205.

24 Tarpley TM, Anderson LG, White CL. Minor salivary gland involvement in Sjögren's syndrome. Oral Surg 1974;37:67-74

25 König G, Lunderschmidt C, Hammer C, Adelmann-Grill $\mathrm{BC}$, Braun-Falco $\mathrm{O}$, Fruhmann $\mathrm{G}$. Lung involvement in scleroderma. Chest 1984;85:318-24.

26 Quanjer $\mathrm{PhH}$, Tammeling GJ, Cotes JE, Pedersen OF, Peslin R, Yernault JC. Lung volumes and forced ventilatory flows. Eur Respir f 1993;6(Suppl 16):5-40.

27 Cotes JE, Chinn DJ, Quanjer Ph H, Roca J, Yernault JC. Standardization of the measurement of transfer factor
(diffusing capacity). Eur Respir $\mathcal{F} 1993 ; 6$ (Suppl 16):41-52.

$28 \mathrm{Klech} \mathrm{H}$, Pohl W. Technical recommendations and guidelines for bronchoalveolar lavage (BAL). Eur Respir $\mathcal{f}$ 1989;2:561-85.

29 Wells AU, Hansell DM, Corrin B, Harrison NK, Gold- straw P, Black CM, et al. High resolution computed tomography as a predictor of lung histology in systemic

30 Harrisson NK, MacAnultry RJ, Haslam PL, Black CM Laurent GJ. Evidence of protein oedema, neutrophil influx, and enhanced collagen production in lungs of patients with systemic sclerosis. Thorax 1990;45:606-10

31 Miller KS, Smith EA, Kinsella M, Schabel SI, Silver RM Lung disease associated with progressive systemic sclerosis. Assessment of interlobar variation by bronchoalveolar lavage and comparison with non invasive evaluation of disease activity. Am Rev Respir Dis 1990;141:301-6.

32 Ramsay SC, Yeates MG, Burke WMJ, Bryant DH, Morgan GW, Breit SN. Quantitative pulmonary gallium scanning

33 Duffy GJ, Thirumurthi K, Casey M, Barker F, Brenan N, Odlum C, et al. Semi-quantitative gallium-67 lung scanning as a measure of the intensity of alveolitis in pulmonary sarcoidosis. Eur $\mathcal{F}$ Nucl Med 1986;12:187-91. 